\section{Evaluating Labor Productivity in a Plant Production System with Sole-source Lighting: A Case Study}

\author{
Katsumi Ohyama ${ }^{1,3}$, Junichi Yamaguchi ${ }^{2}$, and Ayumi Enjoji ${ }^{2}$
}

ADDITIONAL INDEX WORDs. Lactuca sativa, relative harvest rate, processing time, plant factory, supply and demand adjustment, vertical farm

SUMMARY. Labor productivity in terms of material value (weight of plants harvested per hour per person) was evaluated for 6 months from the start of operations in a research facility at Osaka Prefecture University (Osaka, Japan), serving as a model system for plant production with sole-source lighting (also referred to as a "vertical farm" or "plant factory"). The research facility is capable of producing lettuce plants (Lactuca sativa) at a maximum production rate of $\approx 5000$ plants/day when the relative harvest rate (i.e., number of plants harvested/maximum potential number of plants harvested) is $100 \%$. However, in the present study, the relative harvest rate at the research facility was in the range of $17 \%$ to $65 \%$ and labor productivity varied from 1.5 to $6.0 \mathrm{~kg} \cdot \mathrm{h}^{-1}$ per person. The evaluation results indicated that increasing the weight of plants harvested and increasing the relative harvest rate was necessary to maintain a high level of labor productivity. The processing time for harvesting was greatest among all plant operations, suggesting the need to reduce the time taken in this operation to increase the labor productivity in the research facility and in other plant production systems with sole-source lighting (PPSLs). This study demonstrates the importance of analyzing labor productivity for increasing the commercial feasibility of PPSLs. However, further long-term investigation with higher relative harvest rates is required for a more definitive conclusion.

$\mathrm{R}$ ecently, large-scale PPSLs have been constructed and started operations. This type of system is generally a closed structure and thermally insulated, so that the inside environmental conditions [e.g., light intensity, air temperature, and carbon dioxide $\left(\mathrm{CO}_{2}\right)$ concentration] are hardly affected by the outside weather. Moreover, because the environmental conditions can be controlled as desired, the appropriate plant size and quality can be continuously harvested all year round. In Japan, the number of PPSLs was reported to be 197 as of Mar. 2017 (Japan Greenhouse Horticulture Association, 2017). Currently, leafy vegetables (e.g., lettuce) are the main products in PPSLs.

Intensive research has been conducted on PPSLs (Kozai et al., 2016), resulting in more PPSLs being completed; however, significant problems have arisen in terms of management

${ }^{1}$ Organization for Research Promotion, Osaka Prefecture University, 1-1 Gakuen-cho, Sakai, Osaka 599-8531, Japan

${ }^{2}$ Osaka Sakai Plant Factory Co., 208-1 Shinpukuji, Sakai, Osaka 587-0013, Japan

${ }^{3}$ Corresponding author. E-mail: ohyama@center. osakafu-u.ac.jp.

https://doi.org/10.21273/HORTTECH03886-17 (e.g., labor management), especially for large-scale systems, and so the cost of labor has become a major factor affecting operating expenses. Ohyama ple cost analysis of a commercial PPSL (maximum production rate: $\approx 7000$ plants/d). The report showed that labor was a major expense, accounting for $27 \%$ of the total expenses. To increase the revenue, the labor cost must be reduced by efficiently using human resources and/or by using mechanization or automation.

In plant production systems with natural lighting (e.g., fields and greenhouses), efficient use of human resources has been investigated through work analyses. For example, Bechar et al. (2007) conducted a time study in a tomato (Solanum lycopersicum) greenhouse based on the direct (2015) reported a case study on a sim- measurement of trellising and harvesting. Vitner and Bechar (2008) used the time study method to measure harvesting in screen houses where ornamental plants were cultivated. Luxhoj and Giacomelli (1990) compared the time-study method and two tabular methods: Element Times for Agriculture tables and the Maynard Operation Sequence Technique tables (Zandin, 2003) for evaluating the operations in a tomato greenhouse. To increase the accuracy and reliability of measuring the processing time, several handheld devices have been developed (Ampatzidis et al., 2012, 2013; Bechar and EbenChaime, 2014; Riemer and Bechar, 2016). However, for PPSLs, there is little information based on a work analysis including the evaluation of labor productivity.

The objective of this study was to evaluate labor productivity in terms of material value for a PPSL, which is defined in this study as the weight of plants harvested per hour per worker. Labor data were collected for 6 months from the start of operations in a research facility at Osaka Prefecture University (Osaka, Japan), where the maximum possible rate of plant production was $\approx 5000$ plants $/ \mathrm{d}$.

\section{Materials and methods}

Plant production system WITH SOLE-SOURCE LIGHTING. A research facility (floor area $\approx 1300 \mathrm{~m}^{2}$ ) at Osaka Prefecture University was used as a model system for plant production with sole-source lighting (Fig. 1). This research facility is capable of producing lettuce plants at a maximum rate of $\approx 5000$ plants $/ \mathrm{d}$. Currently, 'Frillice' and 'Flarebell' lettuce plants were produced in the research facility. Commercial production at this facility is relatively small in scale; however, in terms of research, it is one of the largest facilities in Japan.

\begin{tabular}{llll}
\hline $\begin{array}{l}\text { Units } \\
\text { To convert U.S. to SI, } \\
\text { multiply by }\end{array}$ & U.S. unit & SI unit & $\begin{array}{l}\text { To convert SI to U.S., } \\
\text { multiply by }\end{array}$ \\
\hline 0.3048 & $\mathrm{ft}$ & $\mathrm{m}$ & 3.2808 \\
0.0929 & $\mathrm{ft}^{2}$ & $\mathrm{~m}^{2}$ & 10.7639 \\
2.54 & inch $(\mathrm{es})$ & $\mathrm{cm}$ & 0.3937 \\
0.4536 & $\mathrm{lb}$ & $\mathrm{kg}$ & 2.2046 \\
28.3495 & $\mathrm{oz}$ & $\mathrm{g}$ & 0.0353 \\
1 & $\mathrm{ppm}$ & $\mathrm{mg} \cdot \mathrm{L}^{-1}$ & 1 \\
$\left({ }^{\circ} \mathrm{F}-32\right) \div 1.8$ & ${ }^{\circ} \mathrm{F}$ & ${ }^{\circ} \mathrm{C}$ & $\left({ }^{\circ} \mathrm{C} \times 1.8\right)+32$
\end{tabular}


The research facility mainly consists of two seedling production rooms, a cultivation room, a workroom, a precooling room, and a cleaning room (Fig. 1). There are two types of rooms for seedling production: one for germination and initial cultivation of the seedlings and the other for the subsequent stage of raising the seedlings, referred to hereafter as room $\mathrm{A}$ and room $B$, respectively.

Room A was equipped with a germination chamber and culture shelves. In the germination chamber, the air temperature was maintained at preferable conditions for germination. The culture shelves were equipped with fluorescent lamps (HF32EX-D-H; Panasonic, Osaka, Japan) or white light-emitting diode (LED) lamps (LDL40S-W/26/21; NEC Lighting, Tokyo, Japan) for raising the seedlings. Air-to-air heat exchangetype heat pumps [FXYFP56MD (indoor), RXUP450CA (outdoor); Daikin Industries, Osaka, Japan] were used to control and cool the air temperature inside room $A$.

Room B was equipped with two multishelves with 17 layers, in which the distance between two layers was $34 \mathrm{~cm}$. In the layers, $\approx 1200$ LED lamps (GreenPower production module DR/W/FR; Philips Lighting Japan, Tokyo, Japan) were installed for raising the seedlings. The multishelves can hold 340 panels $(60 \times 90 \mathrm{~cm})$ with 153 holes each that hold the seedlings. The deep flow technique was used to apply the nutrient solution to the seedlings. The air temperature inside room $B$ was controlled by air-to-air heat exchange-type heat pumps (SZVCP450J; Daikin Industries).

The cultivation room was equipped with six multishelves with 16 or 18 layers, in which the distance between two layers was 40 or $34 \mathrm{~cm}$, respectively. In the layers, $\approx 11,000$ LED lamps (GreenPower production module DR/W/FR; Philips Lighting Japan) were installed for the cultivation of lettuce plants. The multishelves can hold 950 panels $(70 \times$ $125 \mathrm{~cm}$ ) with 30 holes each for holding plants. In the trays, the nutrient solution was applied by using the nutrient film technique. In addition, the trays in the cultivation room were transported by an automatic transferring machine. To cool the air inside the cultivation room, air-to-air

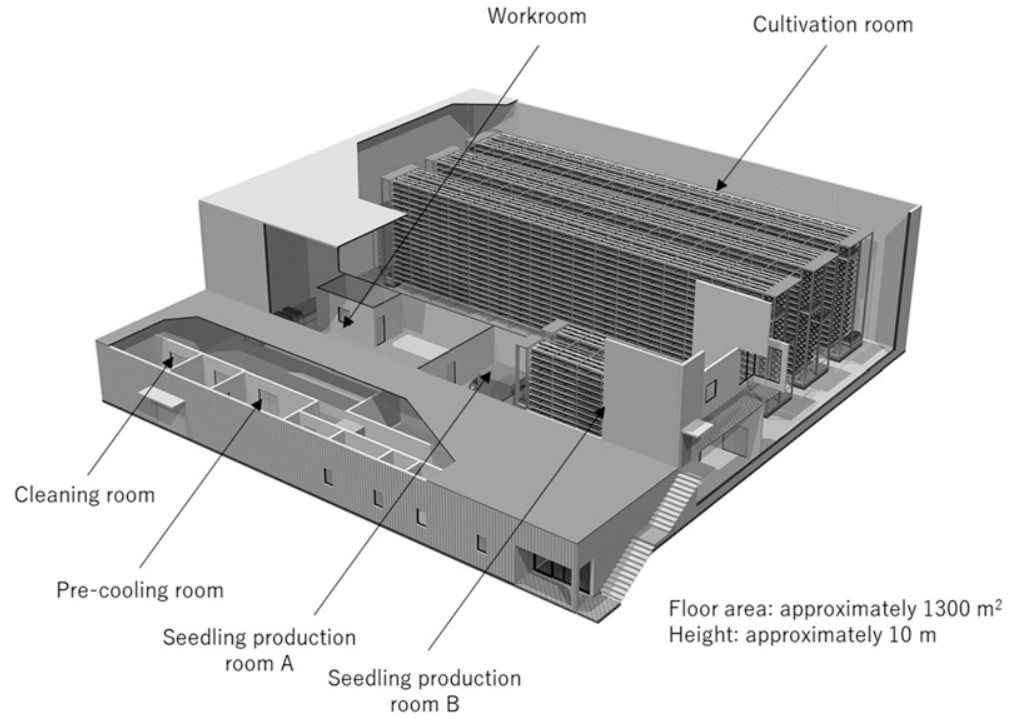

Fig. 1. Schematic diagram of the plant production systems with sole-source lighting at Osaka Prefecture University, Osaka, Japan; $1 \mathrm{~m}^{2}=10.7639 \mathrm{ft}^{2}, 1 \mathrm{~m}=3.2808 \mathrm{ft}$.

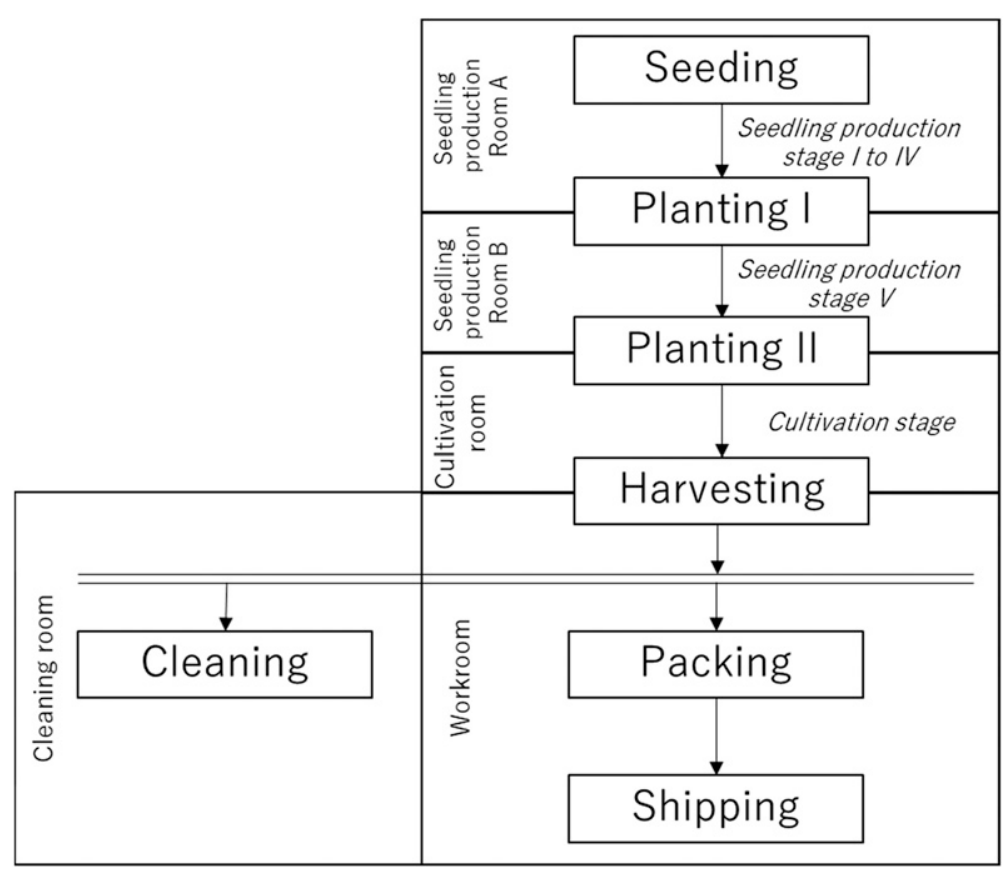

Fig. 2. Schematic diagram of the operations in the plant production systems with sole-source lighting, where lettuce plants were produced. To clarify the relationship between the operations, production stages, and rooms, the corresponding production stages and rooms are noted between the operations. In the seedling production room $\mathrm{A}$, seedling production stages I to IV were conducted (see Table 1 ). In the seedling production room B, seedlings with two to three true leaves were grown (seedling production stage V). In the culture room, seedlings with four to five true leaves were transplanted and grown for $38 \mathrm{~d}$ ('Frillice') or $40 \mathrm{~d}$ ('Flarebell'). In the workroom, lettuce plants were harvested, processed, and packed. Then, packed plants were stored in the precooling room. When cleaning panels used in the hydroponic system, the cleaning room was used.

heat exchange-type heat pumps with air ducts (SZVYP2240J; Daikin Industries) were installed. The temperature of the nutrient solution was not controlled. All sensors employed in the research facility were calibrated periodically (6-12 months) or when necessary. 
Table 1. Culture conditions of lettuce plants during the seedling production and cultivation periods in the plant production systems with sole-source lighting.

\begin{tabular}{|c|c|c|c|c|c|c|}
\hline Growth stage & Period (d) & $\begin{array}{l}\text { Planting density } \\
\left(\text { plants } / \mathrm{m}^{2}\right)^{\mathrm{z}}\end{array}$ & $\begin{array}{c}P P F D \\
\left(\mu \mathrm{mol} \cdot \mathrm{m}^{-2} \cdot \mathrm{s}^{-1}\right)^{\mathrm{y}}\end{array}$ & $\begin{array}{l}\text { Photoperiod } \\
\left(\mathbf{h} \cdot \mathrm{d}^{-1}\right)\end{array}$ & $\begin{array}{c}\text { Air temp } \\
{\left[\text { light } / \text { dark }\left({ }^{\circ} \mathrm{C}\right)\right]^{\mathrm{z}}}\end{array}$ & $\begin{array}{c}\mathrm{CO}_{2} \text { concn } \\
\left(\mu \mathrm{mol} \cdot \mathrm{mol}^{-1}\right)^{x}\end{array}$ \\
\hline Seedling production stage I & 2 & 1,667 & 0 & 0 & 24 & - \\
\hline Seedling production stage II & 2 & 1,667 & 120 & 16 & $24 / 21$ & 800 \\
\hline Seedling production stage III & 1 & 1,667 & 120 & 16 & $24 / 21$ & 800 \\
\hline Seedling production stage IV & 4 & 1,667 & 120 & 16 & $24 / 21$ & 800 \\
\hline Seedling production stage $\mathrm{V}$ & $\begin{array}{l}12 \text { ('Frillice') } \\
14 \text { ('Flarebell') }\end{array}$ & 283 & 200 & 15 & $24 / 21$ & 800 \\
\hline
\end{tabular}

${ }^{\mathrm{z}} 1$ plant $/ \mathrm{m}^{2}=0.0929$ plant $/ \mathrm{ft}^{2},\left(1.8 \times{ }^{\circ} \mathrm{C}\right)+32={ }^{\circ} \mathrm{F}$.

${ }^{\mathrm{y}} \mathrm{PPFD}$ on the tray or panel surface.

${ }^{x}$ Carbon dioxide concentration was not controlled during Stage I.

$P P F D=$ photosynthetic photon flux density.

Operations IN THE RESEARCH FACILITY. A flow diagram summarizing the operations in the research facility is shown in Fig. 2. In seedling production stage $\mathrm{I}$, seeds were sown on urethane foam sheets $(30 \times 60 \mathrm{~cm})$ with 300 holes in room A (seeding). After the seeds were sown, the trays with the urethane foam were placed in the germination chamber for $2 \mathrm{~d}$. After the seeds germinated, the trays were transferred to the culture shelves with white fluorescent lamps and cultured for $2 \mathrm{~d}$ during stage II. Then, the urethane foam was placed on other trays $(60 \times 60 \mathrm{~cm})$ and cultured for $1 \mathrm{~d}$ on the same shelf during stage III, after which the trays were transferred to another culture shelf and placed under LED lamps for $4 \mathrm{~d}$ during stage IV. During stage $V$, the seedlings were automatically transferred to the 153-hole panel $(60 \times$ $90 \mathrm{~cm}$ ) and moved to room B (planting I) where they were grown for $12 \mathrm{~d}$ ('Frillice') or $14 \mathrm{~d}$ ('Flarebell').

During the cultivation stage, the seedlings were planted manually on 30-hole panels (planting II) and grown for $17 \mathrm{~d}$ in the cultivation room. The 30-hole panels were transferred automatically from the cultivation room to the workroom by the transferring machines and a conveyer. Then, the plants were harvested manually and deteriorated and/or surplus leaves were removed (harvesting). When the harvesting was completed, the plants were packed with plastic film (packing), placed in cartons, and stored in the precooling room until being shipped to customers (shipping). During the harvesting, the trays and panels used in the seedling production and cultivation stages were collected and transferred to the cleaning room, where they were washed in preparation for the next use (cleaning).

The operations of the research facility started on 1 Feb. 2017. Before this, trial production of lettuce plants was conducted for $\approx 4$ months, during which suitable culture conditions for lettuce production were examined, and the workers were trained.

Culture conditions. Because the culture conditions and the nutrient solution were determined and amended by the facility managers based on their observations of plant growth and development, standard conditions were described in this article. Culture conditions currently employed in the research facility are shown in Table 1. During seedling production stage I, photosynthetic photon flux density (PPFD) and air temperature were, respectively, set at $0 \mu \mathrm{mol} \cdot \mathrm{m}^{-2} \cdot \mathrm{s}^{-1}$ (continuous darkness) and $24^{\circ} \mathrm{C}$. After stage I, PPFD and air temperature were set at $\approx 120-200$ $\mu \mathrm{mol} \cdot \mathrm{m}^{-2} \cdot \mathrm{s}^{-1}$ with a 15 - or 16 -h photoperiod and $24 / 21{ }^{\circ} \mathrm{C}$ (light/dark period). The $\mathrm{CO}_{2}$ concentrations inside the seedling production rooms except for the germination chamber were maintained at $800 \mu \mathrm{mol} \cdot \mathrm{mol}^{-1}$. Nutrient solution containing nitrogen, phosphorus, and potassium at 130,20 , and $150 \mathrm{mg} \cdot \mathrm{L}^{-1}$, respectively, with a $\mathrm{pH}$ of 4.7 was applied during each growth stage.

\section{Measurements and estimations}

LETTUCE PRODUCTION IN THE RESEARCH FACILITY. The number of harvested 'Frillice' and 'Flarebell' lettuce plants was recorded manually during the research period of $181 \mathrm{~d}$ (6 months). Growth parameters, including the fresh weight of the head, root, and marketable head, and the number of leaves and plant height were determined at 103, 111, 119, 126, 134, and $142 \mathrm{~d}$ ('Frillice') or $111,120,126,134,142$, and $149 \mathrm{~d}$ ('Flarebell') after the start of operations. Fresh weight of the head and root was measured with an electric balance (PL602; Mettler Toledo, Greifensee, Switzerland) at $37 \mathrm{~d}$ ('Frillice') or $39 \mathrm{~d}$ ('Flarebell') after sowing. By trimming the deteriorated and/or surplus leaves, the fresh weight of the marketable head was determined. At the same time, the number of leaves and the plant height were also measured. The total weight of plants harvested was determined by multiplying the number of plants harvested and the fresh weight of the marketable heads.

LABOR PRODUCTIVITY. Labor productivity was estimated by dividing the weight of all plants harvested by the total work hours. The number of workers and the work hours were collected from a time recorder system. Data collected from 0 to $181 \mathrm{~d}$ after the start of operations were used in the present study. However, the estimation of labor productivity excluded the data collected at $121 \mathrm{~d}$ after the start of operations because the production of lettuce plants was temporarily stopped for $1 \mathrm{~d}$ because of renovation of the research facility.

PROCESSING TIME FOR OPERATIONS. The processing time for each operation was estimated from the data on the labor assignment table and the work hours of the respective workers. Data were collected from 150 to $181 \mathrm{~d}$ after the start of operations (1 month).

Statistical analyses. Data on plant growth and development were 
Table 2. Fresh weight, number of leaves, and height of the lettuce plants harvested in the plant production systems with solesource lighting at $37 \mathrm{~d}$ ('Frillice') or $39 \mathrm{~d}$ ('Flarebell') after sowing.

\begin{tabular}{lccccc}
\hline & \multicolumn{3}{c}{ Fresh wt $[\text { mean } \pm \text { SD }(\mathrm{g})]^{\mathrm{z}}$} & & \\
\cline { 2 - 6 } Cultivar & Head & Root and urethane cube & Marketable head & Leaves $[$ mean \pm SD $($ no. $)]$ & Plant ht $[\text { mean } \pm \text { SD }(\mathrm{cm})]^{\mathrm{z}}$ \\
\hline Frillice & $111.0 \pm 11.6 \mathrm{a}^{\mathrm{x}}$ & $9.1 \pm 0.5 \mathrm{~b}^{*}$ & $102.8 \pm 5.6 \mathrm{a}^{*}$ & $23.3 \pm 0.4 \mathrm{~b}^{*}$ & $15.4 \pm 0.5 \mathrm{a}^{*}$ \\
Flarebell & $89.5 \pm 7.9 \mathrm{~b}^{*}$ & $12.1 \pm 0.7 \mathrm{a}^{*}$ & $75.3 \pm 4.2 \mathrm{~b}^{*}$ & $34.7 \pm 0.5 \mathrm{a}^{*}$ & $13.6 \pm 0.6 \mathrm{~b}^{*}$ \\
\hline
\end{tabular}

${ }^{\mathrm{z}} \mathrm{l} \mathrm{kg}=2.2046 \mathrm{lb}, \mathrm{l} \mathrm{cm}=0.3937$ inch.

${ }^{\mathrm{y}}$ The fresh weight of root part with the urethane cube was measured. The weight of urethane cube was $\approx 0.5 \mathrm{~g}(0.018 \mathrm{oz})$ per cube.

${ }^{x}$ Any two means within a row not followed by the same letter are significantly different $(P<0.01)$ based on the Mann-Whitney $U$ test.

$\mathrm{SD}=$ standard deviation.
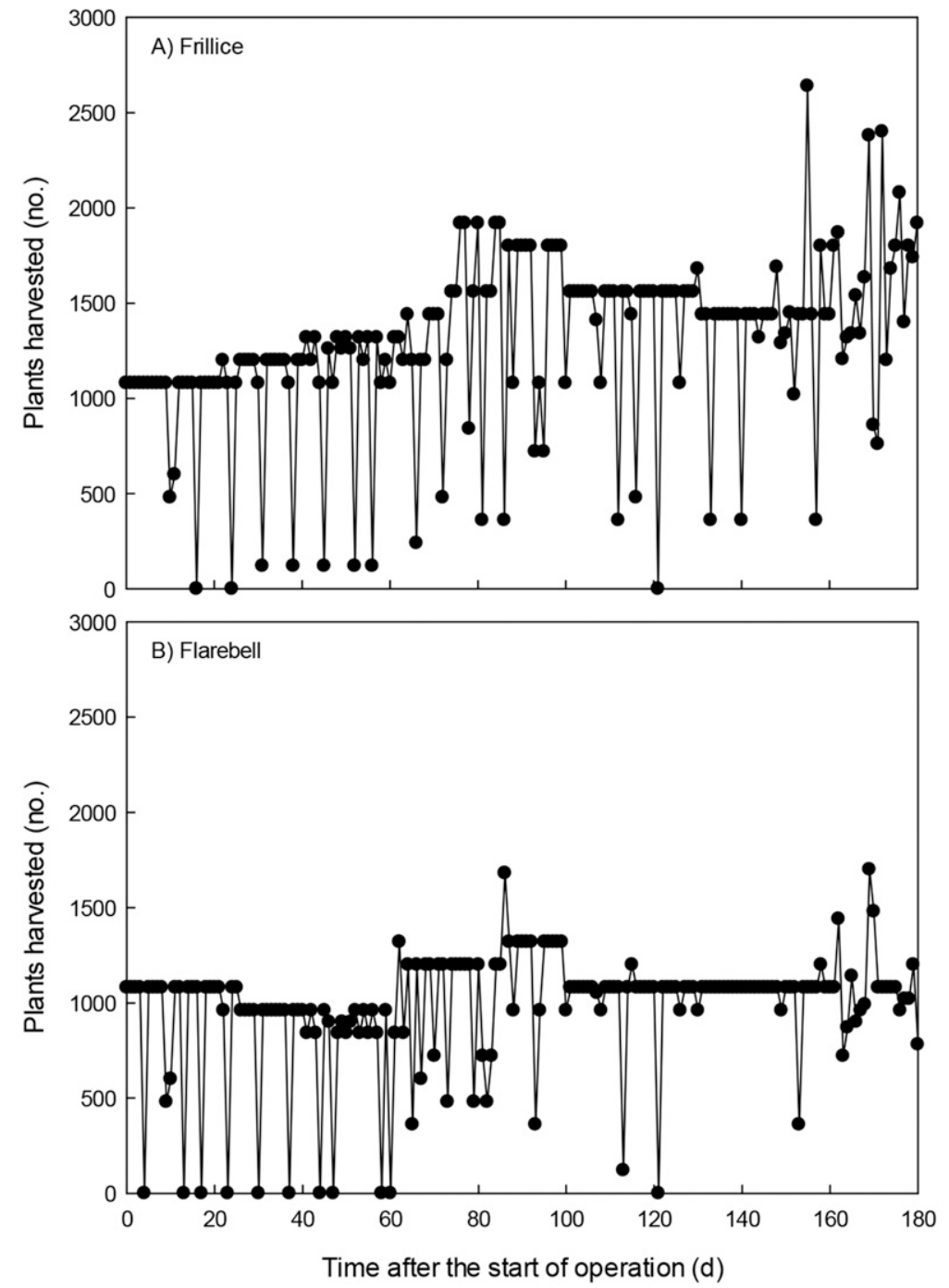

Fig. 3. Time courses of the daily number of lettuce plants harvested in the plant production systems with sole-source lighting: (A) 'Frillice' and (B) 'Flarebell.' A planned operation stop occurred at $121 \mathrm{~d}$ after the start of operations because of renovation of the plant production system.

subjected to the Mann-Whitney $U$ test to identify differences between the two cultivars. Linear regression analysis was conducted to clarify the effects of the weight of plants harvested and the relative harvest rate of the research facility on the labor productivity. To detect differences among the operations, the processing time was subjected to the TukeyKramer test. Statistical analyses were conducted using R statistical software (R Core Team, 2017).

\section{Results and discussion}

LETTUCE PRODUCTION IN THE RESEARCH FACILITY. Based on the trial production, the lettuce plants could be successfully produced from the start of operations at the research facility. Although consistent culture conditions were applied at the facility, the growth and development of 'Frillice' lettuce plants differed from those of 'Flarebell' lettuce plants (Table 2). The fresh weight of the marketable head was greater in 'Frillice' than in 'Flarebell.' The fresh weight of the head and the plant height were also greater in 'Frillice' than in 'Flarebell'; however, the fresh weight of the root and the number of leaves were smaller in 'Frillice' than in 'Flarebell'.

Time courses of the number of 'Frillice' and 'Flarebell' lettuce plants harvested are shown in Fig. 3A and B, respectively. Because the fresh weight of the marketable head in 'Frillice' and 'Flarebell' lettuce plants differed from each other, the weight of plants harvested was estimated separately for each cultivar. The aggregated results are shown in Fig. 4.

Because of the fluctuation in demand for the lettuce plants, the number (Fig. 3) and weight (Fig. 4) of plants harvested varied. Accordingly, the relative harvest rate (Fig. 5) and the number of workers and work hours were adjusted almost every day by the facility managers. If changes in the demand for the lettuce plants could be kept small, fluctuations in the number of workers and work hours could be minimized. This would reduce the time for adjusting the shift schedule of workers in the research facility.

LABOR PRODUCTIVITy. Figure 6 shows the time course for labor productivity, which can be seen to fluctuate in the range from 1.5 to $6.0 \mathrm{~kg} \cdot \mathrm{h}^{-1}$ per person. During the research period of 6 months, a large fluctuation in labor productivity was observed. This is possibly because of a failure to adjust the forecast for lettuce supply and demand, resulting in drops in the relative harvest rate 


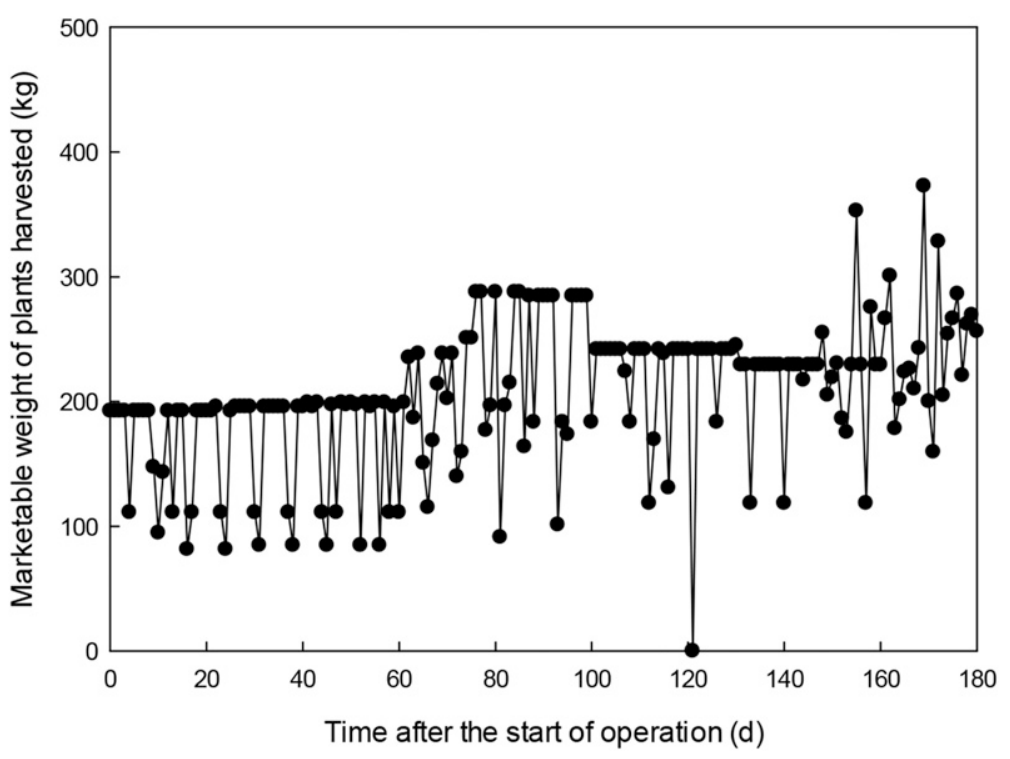

Fig. 4. Time course of the weight of lettuce plants harvested in the plant production systems with sole-source lighting. A planned operation stop occurred at $121 \mathrm{~d}$ after the start of operations because of renovation of the plant production system; $1 \mathrm{~kg}=2.2046 \mathrm{lb}$.

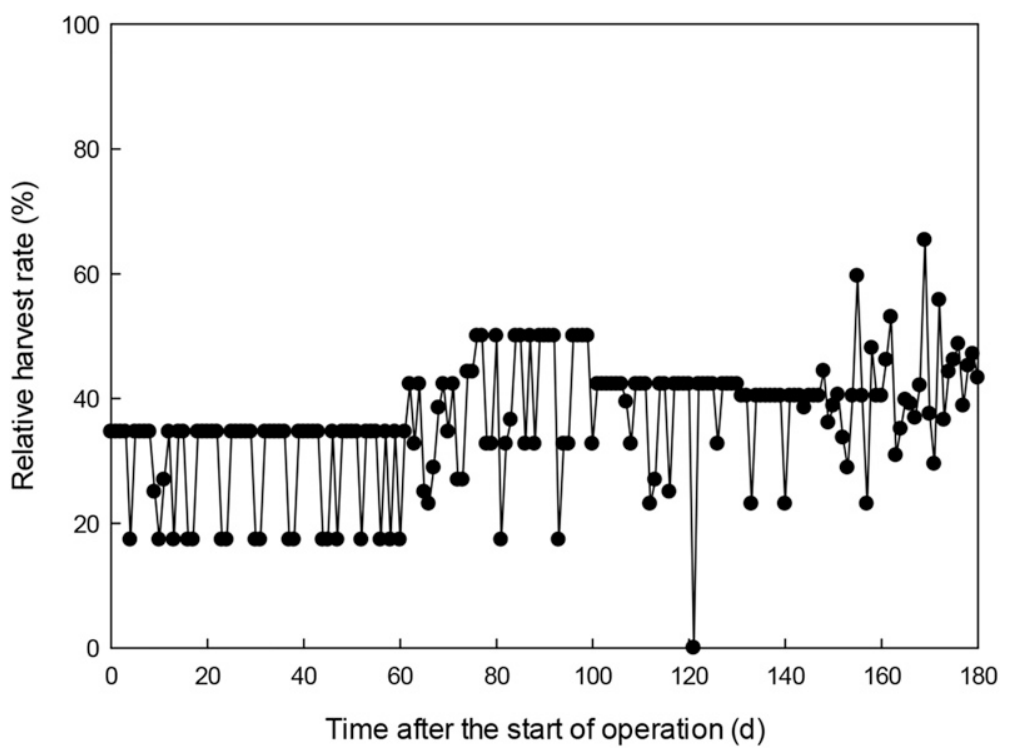

Fig. 5. Time course of the relative harvest rate of the plant production systems with sole-source lighting, where lettuce plants were produced. A planned operation stop occurred at $121 \mathrm{~d}$ after the start of operations because of renovation of the plant production system. The relative harvest rate was defined as the daily number of lettuce plants harvested by the maximum potential number of plants harvested.

resulting from too many available workers. Hence, to achieve high labor productivity, it is necessary to maintain the relative harvest rate at a higher level through appropriate adjustment of the supply and demand.

By increasing lettuce weight of plants harvested (Fig. 7) and the relative harvest rate (Fig. 8), labor productivity was increased. To achieve and maintain a higher level the maximum number of plants harvested was 10,300 plants $/ \mathrm{d}$. In that PPSL, the number of work hours per marketable head $(82 \mathrm{~g} /$ plant on average) was 0.84 person-minute. From this information obtained in the PPSL, in which the worker proficiency was expected to be higher than that in the research facility, the roughly estimated value for labor productivity was $5.9 \mathrm{~kg} \cdot \mathrm{h}^{-1}$ per person $(82 \mathrm{~g} / 0.84$ person-minute). This value is comparable to the value we obtained when the relative harvest rate was $65 \%$. Hence, labor productivity will increase with increasing the weight of plants harvested and the relative harvest rate.

There are two types of labor productivity: one in terms of material value and the other in terms of monetary value; this article deals only with the former. In the research facility, the material value will be increased only if 'Frillice' lettuce plants were grown. This is because the fresh weight of the marketable head was 1.35 times greater for 'Frillice' lettuce plants than for 'Flarebell' lettuce plants (Table 2). By contrast, labor productivity in terms of monetary value (i.e., sales per hour per person) was unaffected by the cultivars grown because the price of the marketable head of 'Frillice' lettuce plants was the same as that of 'Flarebell' lettuce plants. To evaluate the commercial feasibility of PPSLs, labor productivity in terms of both material and monetary value should be investigated. In addition, in this study, labor productivity in terms of monetary value ranged between 1740 and 6610 yen $/ \mathrm{h}$ per person $(\approx \$ 16 / \mathrm{h}$ to $60 / \mathrm{h}$ per person), if the wholesale price of the marketable head is assumed to be 100 yen $(\approx \$ 0.91)$.

Here, a simple economic analysis was performed under the following assumptions: 1) the daily depreciation cost of PPSL is 137,000 yen (construction cost for PPSL is 500 million yen, amortized over 10 years), 2) the daily electricity cost is 120,000 yen, 3 ) the daily labor cost is 96,000 yen (12 laborers work for $8 \mathrm{~h}$ in the PPSL every day and the hourly pay is 1000 yen/h per person), and 4) the daily material cost, including water, nutrients, urethane foam, is 20,000 yen. These assumptions were based on a survey of several PPSLs. Based on these assumptions, the total cost is 


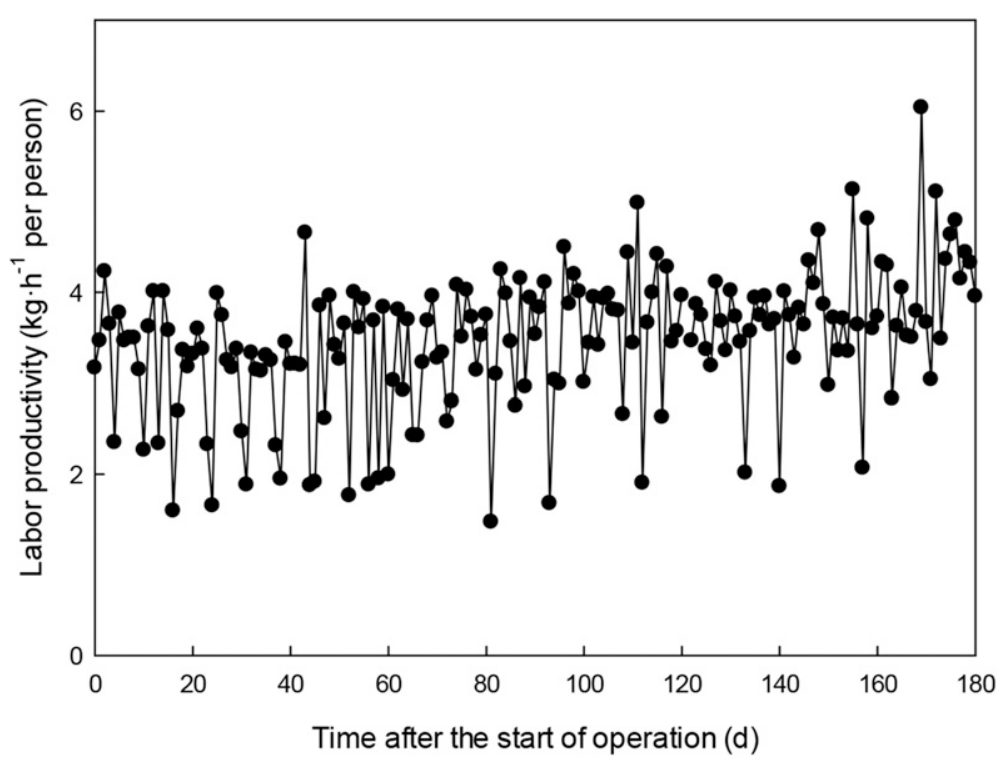

Fig. 6. Time course of the labor productivity in the plant production systems with sole-source lighting, where lettuce plants were produced. Data collected at $121 \mathrm{~d}$ after the start of operations were excluded because of a planned operation stop because of renovation of the facilities inside the plant production system; $1 \mathrm{~kg}=2.2046 \mathrm{lb}$.

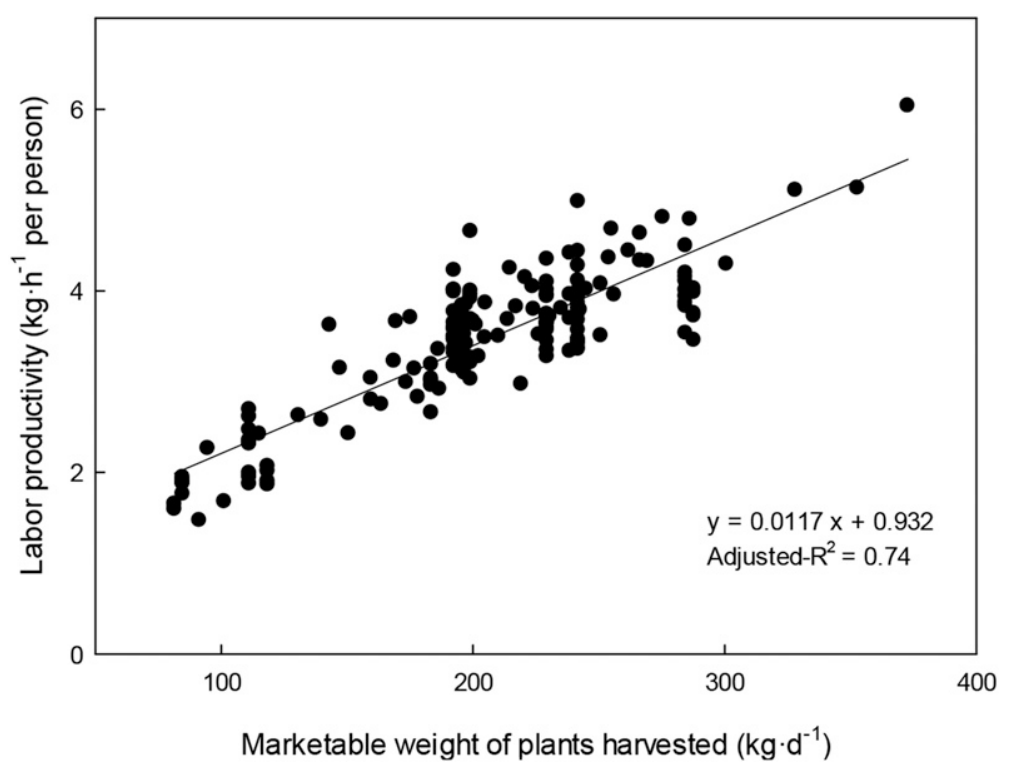

Fig. 7. Effect of the weight of lettuce plants harvested on labor productivity in the plant production systems with sole-source lighting $(n=180) ; 1 \mathrm{~kg}=2.2046 \mathrm{lb}$.

estimated to be 373,000 yen. Hence, to avoid the cost for lettuce production exceeding the revenue, the labor productivity should be greater than $3.2 \mathrm{~kg} \cdot \mathrm{h}^{-1}$ per person $[373,000 \mathrm{yen} /$ (100 yen $/ 0.082 \mathrm{~kg}) / 12$ persons/ 8 h]. Because the other daily production costs (e.g., transportation and operating expenses) were not included in this estimation, the value obtained may be underestimated. To conduct a more accurate estimation, further investigations are required.
In this study, a linear relationship was found between labor productivity and the weight of the plants harvested (Fig. 7). A linear relationship was also found between labor productivity and the relative harvest rate at the research facility (Fig. 8). However, residuals were observed in the regression analyses in both cases, possibly because of the daily variation in worker efficiency. Although consistent efficiency is desirable, workers and their roles were changed every day and only 6 months had passed since the start of operations. Over time, it is expected that the residuals in Figs. 7 and 8 will become smaller.

Labor productivity increased with increasing weight of plants harvested (Fig. 7) and increasing relative harvest rate (Fig. 8). This may be because the time required for common tasks, including preparation and cleaning, could account for a large proportion of the work hours under the conditions of smaller weight of plants harvested and reduced relative harvest rates. With larger weight of plants harvested and/or relative harvest rate, labor productivity will be greater because the proportion of common tasks will be lower.

In the present study, the number of plants harvested was recorded manually. Harvested plants were shipped in three product forms: individual plant wrapping, multiple plant wrapping, and discrete leaf wrapping. Lettuce plants that did not meet the criteria for individual or multiple wrapping were separated into leaves. In this way, the loss of lettuce plants during harvesting to shipping was minimized, but small losses could occur during harvesting and packing. These may cause a difference between the manually recorded values and the actual shipments, and hence labor productivity in the results may be overestimated.

PROCESSING TIME FOR OPERATIONS. The processing time for each operation is shown in Fig. 9. The greatest processing time was observed in harvesting, which accounted for $37 \%$ of the total processing time. This was because the harvesting operation includes time-consuming tasks (e.g., removing the deteriorated and/or surplus leaves from the lettuce plants harvested). The operations from the harvesting onward (harvesting, packing, shipping, and cleaning) accounted for $78 \%$ of the total processing time. If the time required for these operations, especially harvesting and packing, could be reduced by automation for example, labor productivity would be significantly increased in the research facility and in other PPSLs.

In the present study, the processing time was estimated from the labor assignment table and the work hours of the respective workers. However, there are several methods for obtaining a more accurate processing time, 


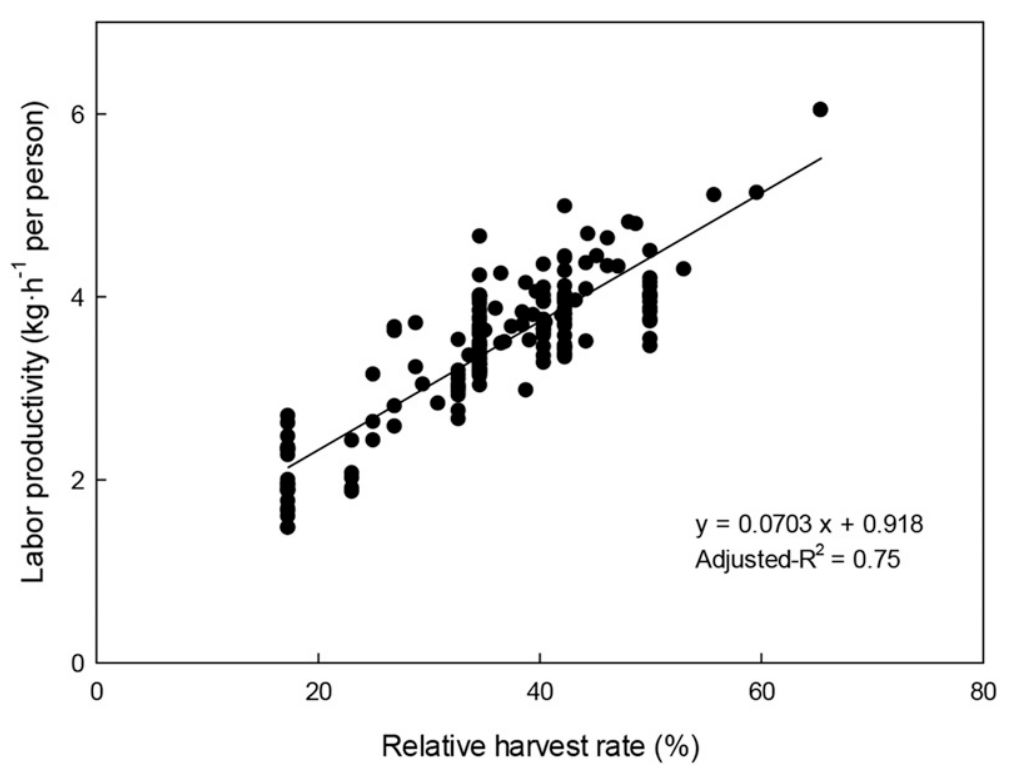

Fig. 8. Effect of the relative harvest rate on labor productivity in the plant production systems with sole-source lighting $(n=180) ; 1 \mathrm{~kg}=2.2046 \mathrm{lb}$.

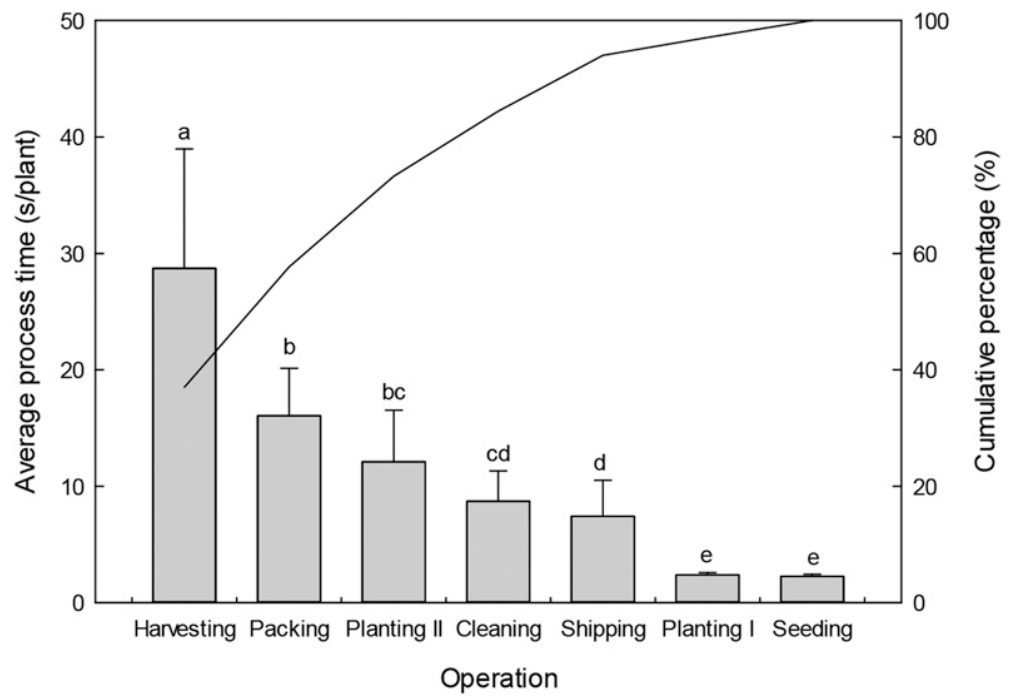

Fig. 9. Pareto chart of the average processing time for seeding, planting I, planting II, harvesting, packing, shipping, and cleaning in the plant production systems with sole-source lighting, where lettuce plants were produced $(n=31)$. This chart contains both bars and a line graph, in which individual values of process times are represented in ranked order by bars, and the cumulative percentage is represented by the line. Means labeled with different letters are significantly different $(P<$ 0.01 ) based on the Tukey-Kramer test. Plantings I and II were conducted in the seedling production room $B$ and the cultivation room (see Fig. 2).

such as the time-study method using direct measurement, which is a common procedure that provides more accurate and reliable results (Aft, 2000; Barnes, 1980; Meyers, 1999; Mital et al., 2017). We intend to use this method in a future study for analyzing the processing time in the research facility.

Transportation between the research facility and customers requires and, thus, we only focus on labor productivity in the research facility.

\section{Conclusion}

Labor productivity in terms of material value was evaluated based on data collected for 6 months from the start of operations in a research facility at Osaka Prefecture University. Within the relative harvest rate range of $17 \%$ to $65 \%$, labor productivity increased with increasing weight of plants harvested and relative harvest rate, indicating the need to increase or maintain both factors to raise labor productivity. An analysis of the processing times for operations showed that harvesting took the most time, so to increase labor productivity, it is essential to reduce the time for harvesting. These results show that the evaluation of labor productivity is beneficial for increasing the commercial feasibility of PPSLs, although further long-term investigation with higher relative harvest rates is necessary.

\section{Literature cited}

Aft, L.S. 2000. Work measurement and methods improvement. Wiley, New York, NY.

Ampatzidis, Y.G., M.D. Whiting, P.A. Scharf, and Q. Zang. 2012. Development and evaluation of a novel system for monitoring harvest labor efficiency. Comput. Electron. Agr. 88:85-94.

Ampatzidis, Y.G., M.D. Whiting, P.A. Scharf, and Q. Zang. 2013. Portable weighing system for monitoring picker efficiency during manual harvest of sweet cherry. Precis. Agr. 14:162-171.

Barnes, R.M. 1980. Motion and time study - Design and measurement of work. Wiley, New York, NY.

Bechar, A. and M. Eben-Chaime. 2014. Hand-held computers to increase accuracy and productivity in agricultural work study. Intl. J. Performance Mgt. 63(2):194-208

Bechar, A., S. Yosef, S. Netanyahu, and Y. Eden. 2007. Improvement of work methods in tomato greenhouses using simulation. Trans. Amer. Soc. Agr. Biol. Eng. 50(2):331-338.

Hirose, S. 2017. Increasing lettuce productivity in a plant factory with sole-source lighting. Greenhouse Hort. 176(Winter):14 18 (in Japanese).

Japan Greenhouse Horticulture Association. 2017. Project report on the 


\section{Research Reports}

regional promotion of next-generation greenhouse horticulture (Supplemental 2). Jpn. Greenhouse Hort. Assn., Tokyo, Japan (in Japanese).

Kozai, T., G. Niu, and M. Takagaki. 2016. Plant factory - An indoor vertical farming system for efficient quality food production. Academic Press, London, UK.

Luxhoj, J.T. and G.A. Giacomelli. 1990. Comparison of labour standards for a greenhouse tomato production system: A case study. Intl. J. Oper. Prod. Mgt. 10(3):38-49.
Meyers, F.E. 1999. Motion and time study for lean manufacturing. 2nd ed. Prentice Hall, Upper Saddle River, NJ.

Mital, A., A. Desai, and A. Mital. 2017. Fundamentals of work measurement What every engineer should know. CRC Press, Boca Raton, FL.

Ohyama, K. 2015. Management status of a large-scale plant production system with sole-source lighting. Greenhouse Hort. 168(Winter):30-33 (in Japanese).

R Core Team. 2017. R: A language and environment for statistical computing. 19 June 2017. <https://www.R-project.org/>.
Riemer, R. and A. Bechar. 2016. Investigation of productivity enhancement and biomechanical risks in greenhouse crops. Biosyst. Eng. 147:39-50.

Vitner, G. and A. Bechar. 2008. Screen house simulation of work processes in green ornamentals. ASABE Paper No. 084882. Amer. Soc. Agr. Biol. Eng., St. Joseph, MI.

Zandin, K.B. 2003. MOST work measurement systems. 3rd ed. CRC Press, Boca Raton, FL. 